\title{
BMJ Open Women's leadership in academic medicine: a systematic review of extent, condition and interventions
}

\author{
Lulu Alwazzan (D) , ${ }^{1}$ Samiah S Al-Angari (D) ${ }^{2}$
}

To cite: Alwazzan $\mathrm{L}$, Al-Angari SS. Women's leadership in academic medicine: a systematic review of extent, condition and interventions. BMJ Open 2020;10:e032232. doi:10.1136/ bmjopen-2019-032232

- Prepublication history and additional material for this paper are available online. To view these files, please visit the journal online (http://dx.doi. org/10.1136/bmjopen-2019032232).

Received 12 June 2019 Revised 24 October 2019 Accepted 26 November 2019

Check for updates

(c) Author(s) (or their employer(s)) 2020. Re-use permitted under CC BY-NC. No commercial re-use. See rights and permissions. Published by BMJ.

${ }^{1}$ Medical Education, Al Imam Mohammed Ibn Saud Islamic University, Riyadh, Saudi Arabia ${ }^{2}$ Otolaryngology, Head \& Neck surgery, King Saud University, Riyadh, Saudi Arabia

Correspondence to

Dr Lulu Alwazzan;

laalwazzan@imamu.edu.sa

\begin{abstract}
Objectives Because culture reflects leadership, the making of diverse and inclusive medical schools begins with diversity among leaders. The inclusion of women leaders remains elusive, warranting a systematic exploration of scholarship in this area. We ask: (1) What is the extent of women's leadership in academic medicine? (2) What factors influence women's leadership? (3) What is the impact of leadership development programmes?

Design Systematic review.

Data sources A systematic search of six online databases (OvidMEDLINE, EMBASE, CINAHL, PsycINF0, the Cochrane Library and ERIC) from the earliest date available to April 2018 was conducted. Bridging searches were conducted from April 2018 until October 2019.
\end{abstract}

Eligibility criteria (1) Peer-reviewed; (2) English; (3) Quantitative studies (prospective and retrospective cohort, cross-sectional and preintervention/postintervention); evaluating (4) The extent of women's leadership at departmental, college and graduate programme levels; (5) Factors influencing women's leadership; (6) Leadership development programmes. Quantitative studies that explored women's leadership in journal editorial boards and professional societies and qualitative study designs were excluded.

Data extraction and synthesis Two reviewers screened retrieved data of abstracts and full-texts for eligibility, assessment and extracted study-level data independently. The included studies were objectively appraised using the Medical Education Research Quality Study Instrument with an inter-rater reliability of $(\kappa=0.93)$.

Results 0 4024 records retrieved, 40 studies met the inclusion criteria. The extent of women's leadership was determined through gender distribution of leadership positions. Women's leadership emergence was hindered by institutional requirements such as research productivity and educational credentials, while women's enactment of leadership was hindered by lack of policy implementation. Leadership development programmes had a positive influence on women's individual enactment of leadership and on medical schools' cultures.

Conclusions Scholarship on women's leadership inadvertently produced institute-centric rather than women-centric research. More robust contextualised scholarship is needed to provide practicalrecommendations; drawing on existing conceptual frameworks and using more rigorous research methods.

\section{Strengths and limitations of this study}

- Unlike other reviews addressing women's careers in academic medicine, this review focuses solely on studies exploring the leadership of women, a central component of gender equity initiatives.

- The systematic approach provided a rigorous framework by which study objectives were set and studies were identified and appraised.

- Exclusion of qualitative literature may limit the conceptual argument of this study.

- Reviewed studies are western, therefore, findings of this review are not generalisable to non-western contexts.

\section{INTRODUCTION}

Inclusivity and diversity are goals every medical school hopes to achieve for its learners and faculty members. ${ }^{1-3}$ An impediment to realising these goals is the culture of academic medicine, commonly criticised for reinforcing gender and ethnic inequalities. ${ }^{4-8}$ By bringing a transformative perspective, women leaders are often thought of as catalysts of organisational culture change, capable of creating better career experiences for the diverse workforce that has come to makeup medical education and practice. ${ }^{9-11}$ Despite the recognition, it has been challenging for scholars to study and develop women's leadership. The difficulty, in part, stems from thecurrent barriers' cultural nature: traditional models of work, ${ }^{11}$ implicit gender bias, ${ }^{12}$ limited access to support systems both mentors ${ }^{9}$ and sponsors, ${ }^{3}$ gender stereotyping, ${ }^{14}$ gendered views of leadership ${ }^{15}$ and culture-abiding self-imposed constraints. ${ }^{16} 17$

Such barriers are, of course, not unique to women leaders or to the context of academic medicine. The wealth of literature exploring women's careers, much of it reviewed in two systematic reviews, ${ }^{12} 18$ one narrative review ${ }^{19}$ and two overviews ${ }^{620}$ conclude that broadly, women faculty face the very same hurdles as they join ${ }^{12}$ and progress in academic medicine 
in their roles as physicians, ${ }^{20}$ teachers ${ }^{18}$ and researchers. ${ }^{19}$ Often, these barriers become reason enough for women to leave academia. ${ }^{21}$ Although these reviews, and the studies within them, broaden our understanding of women's experiences, they have treated women's leadership as ancillary to a bigger discourse on career progression, often coming to leadership as one solution to gender inequity. By doing so, these reviews ignore the centrality of leadership in shaping culture and the change needed to realise gender equity. The current systematic review, therefore, aims to address this gap in the research by exclusively reviewing literature on women's leadership in academic medicine.

\section{BACKGROUND}

In the quest to provide patient-centred care, safe learning environments for trainees and engaging work environments for faculty, the culture of medical education and practice became an area of much scrutiny. ${ }^{521-24}$ Hostility, disrespect, abuse and discrimination are widely documented (eg, USA, ${ }^{21}{ }^{25-28}$ Canada $^{29-31}$ and UK ${ }^{32-34}$ ) as normalised behaviours. The National Initiative on Gender, Culture and Leadership in Medicine: C-Change has benchmarked the culture of academic medicine from the perspective of faculty and with special regard to gender equity, both in the USA and internationally. ${ }^{35}$ As the fulcrum of several studies, ${ }^{45} 21232436-41$ C-Change links unhealthy behaviours to culture, and summates that for culture to change, underpinning values need to change first.

But how do values change? According to the organisational literature, cultural values are the values of founding leaders, are adopted by subsequent leaders and members of the culture, and are kept firmly in place by policies and procedures that were developed and implemented over time. ${ }^{42}{ }^{43}$ Although the dynamic interplay between these forces is important, we draw attention to the locus, cultural values are ultimately the values of leaders. In his 2007 speech 'Culture and the courage to change', ${ }^{44}$ the American Association of Medical Colleges President Kirch spoke to this very point '.. This new culture also requires a different kind of leader ... search committees will need to look far beyond the weight of a candidate's curriculum vitae, considering factors such as their ability to build alignments, foster trust, and make adaptive changes'. ${ }^{44}$

Against the backdrop of need for culture change and a leadership to see it through, we take up women's leadership in academic medicine, often viewed as both saviour and victim of culture. ${ }^{82}$ Such a portrayal illustrates the inevitable role women must play as leaders, especially given their increased numbers, ${ }^{10}$ but it also indicates conceptual immaturity. From the emerging conceptual discourse, ${ }^{10} 1745-47$ we know that scholarship on women's leadership lacks depth, where leadership emergence is commonly restricted to the pipeline metaphor, while enactment of it remains grounded in the generic leadership literature.

\section{Leadership emergence}

How women emerge as leaders is often conceptualised using the pipeline metaphor. The metaphor suggests that increasing the number of women in male-dominated fields will eventually lead to an increase in the number of women leaders. According to Magrane and Morahan ${ }^{10}$ the metaphor misses pertinent organisational nuances, namely the implicit gender bias women face. For example, while men have many role models and a robust support system, women do not. The metaphor falsely assumes the presence of role models at the end of the pipeline willing to help women transition to leadership. Given the conceptual limitation, the authors propose frameworks that recognise the complex organisational systems women must navigate to emerge as leaders: the leadership continuum ${ }^{47}$ and systems of career influences. ${ }^{45}$ Such frameworks prompt us to ask questions about the emergence of women's leadership. For example, whether women self-nominate or are appointed to leadership positions in what Northouse ${ }^{43}$ calls assigned leadership, how long they hold leadership positions, whether they go on to hold dual leadership appointments, and if they indeed have mentors or sponsors who support their careers?

\section{Leadership enactment}

Much of women's leadership studies remain grounded in the broader leadership literature. ${ }^{17}$ As a result, our conceptualisations of leadership enactment draw on theories developed on the study of male leaders, making such scholarship inherently male. For example, the older 'great man' theory exclude women entirely, associating leadership with agentic qualities, e.g. authoritative and assertive, qualities that women supposedly do not possess. Newer collaborative theories, for example, participatory, distributed and transformational leadership seem accommodating for women leaders because of their emphasis on social accountability and collaborative work, however, they risk trapping women in gender stereotypes, e.g. nurturing, that nominate women for less prestigious leadership positions e.g. course coordinator.

A more nuanced conceptualisation of leadership enactment may offer new insights that would help us address stereotyping. For example, women may take on informal leadership roles, in what Northouse ${ }^{43}$ calls emergent leadership, referring to leadership that develops organically and is based on building alignments and fostering trust. Our understanding may be expanded by exploring the values that inform women's decisions, the behaviours they model and the actions they take to improve the quality of medical education and practice whether formally or informally. Addressing these gaps situates women leaders as critical actors in culture change $\mathrm{e}^{224547}$ and begins to conceptually ground women's enactment of leadership in their lived experiences, rather than the broader generic leadership literature. ${ }^{17}$ 
It is with the wider need for culture change in academic medicine and the more focused need for conceptual understanding of women's leadership studies in mind that we systematically reviewed studies on women's leadership in academic medicine. It is our aim to first synthesise work done in this area. We ask: (1) What is the extent of women's leadership? (2) What factors influence women's leadership? (3) What is the impact of leadership development programmes on women's individual careers and on medical schools' cultures? We concede that our research questions are broad in scope. We believe it is necessary to cross-cut through these interconnected areas to meet our second aim, which is to present an analysis of such works in the field and critique their collective conceptual framework. We concern ourselves, not only with what was done thus far, but how produced knowledge helps or hinders women's leadership.

\section{METHODS}

\section{Eligibility criteria}

Search results were independently reviewed against a set of a priori inclusion criteria that included all peerreviewed (1) English-language articles; with (2) quantitative methodologies (prospective and retrospective cohort, cross-sectional and preintervention/postintervention); reporting studies that evaluated (3) the extent of women's leadership in academic medicine at a departmental, college and medical graduate programme level; (4) hindering factors to women's leadership as perceived by women and men faculty members and leaders; (5) studies that document leadership interventions and their efficacy as reported by women participants of such programmes and their home medical schools. We included a case study because it presented quantitative descriptive information on women in leadership across non-western multinational settings. Although we recognise the interconnection, we excluded quantitative studies that explored women's leadership in professional societies, journal editorial boards and journal editorships, focusing our examination solely on leadership within medical schools and graduate residency programmes. qualitative study designs were excluded.

\section{Information sources}

A primary systematic search was conducted by the first author between April and May 2018 to cover the publication period of earliest date available to April 2018 using the following databases: (1) Ovid MEDLINE (1946-May 2018); (2) EMBASE (1974-May 2018); (3) CINAHL (1989-May 2018); (4) Ovid PsycINFO (1967April 2018); (5) all EBM Reviews on Ovid-ACP Journal Club, Cochrane Database of Systematic Reviews, Database of Abstracts of Reviews of Effects and Cochrane Central Register of Controlled Trials (first quarter); (6) ERIC (1965-April 2018). In addition, experts in the field were identified and contacted for published studies not revealed through the databases search. Secondary database searches were performed during the submission process to find additional pertinent material (following the same primary search strategy) to cover the period of April 2018 to 14 October 2019. The first author followed a systematic and rigorous plan according to best review practices. A librarian's help was not available. Following the Preferred Reporting Items for Systematic Reviews and Meta-Analyses protocol (PRISMA), ${ }^{48}$ she then screened the compiled results, excluding irrelevant articles and inductively developed a preliminary thematic framework (figure 1).

\section{Search strategy}

Systematic searches were performed on the selected six online bibliographical databases using a combination of key terms including, but not limited to, "women", "female", "females", "girl", "girls", "leadership", "leader", "academic medicine" and "medical education". The keywords were searched for in the "title" and "abstract" search fields. The searches were filtered by applying the inclusion criteria and literature was identified by using keywords and applying Boolean operators 'OR' and 'AND'. Key terms were defined based on the preliminary readings of the literature to ensure the comprehensiveness of our search key terms. For example, "Women", in our search context included articles with a clear indication that the participants in the published studies identified as "females". The literature did not differentiate between sex at birth and gender identity in women's leadership. As a result, we do not differentiate sex and gender in this review. An example of a database search strategy is as follows:

"MEDLINE search: Ovid

1. (Women or woman or female or females or girl or girls).mp. [mp=title, abstract, original title, name of substance word, subject heading word, floating subheading word, keyword heading word, organism supplementary concept word, protocol supplementary concept word, rare disease supplementary concept word, unique identifier, synonyms]

2. limit 1 to English language

3. (Leadership or Leader or leaders or leading).mp. $[\mathrm{mp}=$ title, abstract, original title, name of substance word, subject heading word, floating sub-heading word, keyword heading word, organism supplementary concept word, protocol supplementary concept word, rare disease supplementary concept word, unique identifier, synonyms]

4. limit 3 to English language

5. (Medical education or academic medicine or health professions education or health profession education or professional development or faculty development).mp. [mp=title, abstract, original title, name of substance word, subject heading word, floating subheading word, keyword heading word, organism supplementary concept word, protocol supplementary concept word, rare disease supplementary concept word, unique identifier, synonyms] 
4024 Records identified through databases

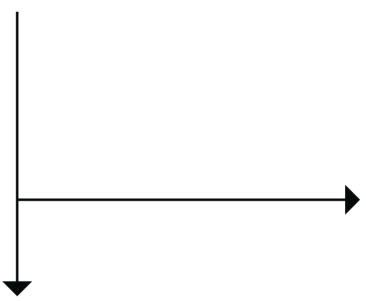

2988 Irrelevant records excluded

\section{Medline \\ 1407 EMBASE \\ 443 CINAHL}

216 PsycINFO

1036 Records after initial screening

183 Medline

78 The Cochrane Library

264 ERIC

363 EMBASE

158 CINAHL

185 PsycINFO

4 The Cochrane Library

143 ERIC

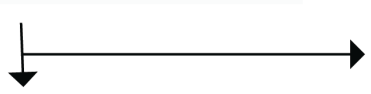

276 Duplicates removed

321 General leadership studies

135 Women's leadership in

education/higher education

162 Gender studies in academic medicine/practice

49 Gender studies in education/higher education

49 Records excluded based on Method/Type of article

21 qualitative/mixed methods studies/case study

93 Full text articles retrieved for further assessment

9 Editorial/Commentary

12 Perspective/essay/review/conceptual paper

7 Conference proceedings

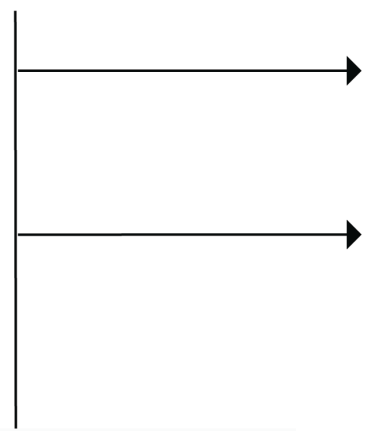

3 Records identified through bibliographies

11 Records excluded based on criteria

1 medical resident leadership 2 leadership interventions that have women participants but are not specific to women.

2 scholarly leadership

2 dental faculty leadership

1 organisational culture study

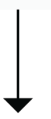

42 Full text articles retrieved for review (40 studies)

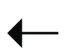

6 records identified through databases April 2018-October 2019

Figure 1 Flowchart of search strategy using Preferred Reporting Items for Systematic Reviews and Meta-Analyses protocol. 
6. limit 5 to English language

7. 2 and 4 and $6 "$

An updated literature search was performed following the same search strategy for the period of April 2018 to October 2019.

\section{Study selection}

Eligibility assessment of the second list of articles titles/ abstracts and thematic framework were independently reviewed by both authors based on the inclusion/exclusion criteria. The full texts of nominated articles were then retrieved and read carefully for data extraction and further assessment. At this stage, the bibliographies of nominated articles were reviewed for potential relevant studies. The two authors discussed their findings and differences were reconciled.

\section{Data collection process}

An Excel spreadsheet was used to collate extracted data. It contained the following information:

1. Details on the eligible study: the first author's name and year of publication as the study ID, title, publication, study period and country.

2. Purpose of the study.

3. Population of interest.

4. Methodological variables: study design, sample size, response rate if applicable and use of validation/reliability measures.

5. Strengths, weaknesses and limitations.

\section{Risk of bias assessment}

We draw on a strategy suggested by the Best Evidence Medical Education Collaboration, ${ }^{49}{ }^{50}$ to provide a narrative of the results. Moreover, using the Medical Education Research Quality Study Instrument (MERSQI), ${ }^{51}$ we give a score and comment on the strength of individual studies, assessing their quality in terms of study design, sampling strategy, type of data, instrument validation, data analysis and outcome measures. The 10-item tool was designed to evaluate quantitative medical education studies, giving a total possible score of $5-18$. The agreement between raters was very good $(\kappa=0.93)$. Where there was disagreement, the authors resolved their differences by discussion. Furthermore, we point out specific methodological issues (eg, lack of contextual demographic or career data, limited population, lack of statistical adjustments and lack of follow-up) not covered by the MERSQI assessment (see online supplementary material 1, Methodological limitations).

\section{Patient and public involvement}

Patients were not directly involved in this systematic review.

\section{RESULTS}

\section{Overview}

The initial database search revealed 4024 citations. Review of the titles and abstracts led to the retrieval of 93 full-text articles for further assessment. In the secondary review, six studies were identified. Forty-two articles met the inclusion criteria and were included in this review (figure 1), three of which were identified through the bibliography search..$^{52-54}$ No studies beyond those identified were revealed by the 17 contacted scholars. Original data were available for 40 studies, described in 42 articles $^{5}{ }^{15} 52-91$ (see online supplementary material 1 for an overview of included studies).

The majority of studies $(n=35)$ were conducted in the USA, six included Canadian respondents, ${ }^{61} 76$ information on Canadian programmes, ${ }^{6077} 79$ or schools' leadership, ${ }^{55}$ one study was conducted across three countries (UAE, Qatar and Singapore), ${ }^{87}$ one study was conducted across three European countries (Sweden, the Netherlands and Austria),${ }^{70}$ one study was conducted across four European countries (Germany, Sweden, Austria and the UK), ${ }^{71}$ one study in Norway ${ }^{72}$ and one study in Croatia. ${ }^{80}$ The earliest study was conducted in $1999,{ }^{72}$ and more than $50 \%$ of the studies were published in the past 5 years alone. The design of nine (26\%) studies was retrospective cohort, ${ }^{15} 5556697680-8288$ one (3\%) prospective cohort $^{58}$ and five (15\%) were preintervention/postintervention. ${ }^{62} 66737586$ Twelve studies were cross-sectional self-reported questionnaires. ${ }^{5616364687083-85878991}$ Where questionnaires were used, the response rates ranged from $22 \%$ to $100 \%$. Thirteen studies were cross-sectional surveys ofpubliclyavailable orarchives ofdata, ${ }^{54575960656769727477-7990}$ and one study was a case report. ${ }^{71}$

Eighteen articles were published by medical education journals, 13 were published by medical specialty journals (Internal Medicine $=3$, Hospital Medicine $=1$, Ophthalmology=1, Obstetrics $/$ Gynecology $=2$, Urology $=2$, Surgery $=1$, Otolaryngology $=1$, Roentgenology $=1$, Radiology $=1$ ), five articles were published by The Women's Health Journal, three by general medicine journals (British Medical Journal=1, the Human Resources for Health Journal=1 and Cureus=1). Finally, one was published by the Journal of Faculty Development.

Many of the studies have methodological limitations. Twelve studies used websites and publicly available data. ${ }^{15} 54-5659636769788790$ Six studies did not reveal how their questionnaires were developed or if they were tested. ${ }^{636566838489} 91$ Many of the questionnaires were self-reported with modest response rates. The preintervention/postintervention studies had small number of participants due to the small number of participants in leadership development programmes. Moreover, nearly all prestudy/poststudy did not present longitudinal findings on the effectiveness of their interventions.

Only eight studies provided contextual demographic (ethnicity or age) and career (career-stage, other leadership appointments, or leadership training) data on the studied populations. ${ }^{5} 55596266708586$ The MERSQI scores of all studies ranged from 7 to 12.5 (online supplementary materials 1 and 2). In what follows, we present our findings grouped according to three themes: the extent of women's leadership and its emergence; factors 
influencing women's leadership emergence and enactment; the impact of leadership programmes on women's leadership enactment.

\section{Extent of women's leadership and its emergence}

Twenty-four studies reported the extent of women's leadership in academic medicine by comparing the number of women attaining leadership positions to the number of men. ${ }^{54-6063676970727477-84879091}$ The studies, however, differed in their approaches and which organisational positions they chose to highlight (table 1). Three studies merely described the representation of women in specialty leadership positions, ${ }^{5767}$ or within a medical school. ${ }^{80}$ One study determined if the proportion of leadership positions in Obstetrics and Gynecology held by women is consistent with the proportion of women entering residency. ${ }^{55}$ Six studies compared the composition of chairs and/or programme directors' gender to faculty members of medical schools, ${ }^{59}{ }^{78-8490}$ five studies compared composition of residency programme directors to medical residents composition, ${ }^{69} 74838490$ while two studies compared the proportion of residents to department chairs. ${ }^{83} 84$ Two studies compared the number of women in leadership positions in one medical specialty to other specialties. ${ }^{569}$

While all studies restricted their study to the gender distribution of leadership positions, three studies $^{63} 7485$ examined leadership emergence (selfnomination vs appointment, length of time in position, dual-leadership appointment and having a mentor/ sponsor). For example, Doyle $e t a l,{ }^{63}$ found that women were assigned to their positions. The authors also found that women leaders on average held positions for 5.3 years compared with men leaders who held positions for 9.1 years.

\section{Factors influencing women's leadership emergence and enactment}

Sixteen articles examined factors associated with leadership gender disparities, ${ }^{5} 155861636668707273757681828688$ revealing that women's leadership emergence was challenged by institutional-level barriers: research productivity requirements, educational requirements, and timing of academic appointment, and an interpersonallevel barrier: perceived lack of mentorship. Leadership enactment, on the other hand, was challenged by an institutional-level barrier: poor gender equality policy development and translation, as well as an interpersonallevel barrier: gender stereotyping (table 2).

On what hinders women's emergence as leaders, three studies investigated research productivity. ${ }^{587081}$ In one study, gender was significantly associated with position through publication activity $(\beta=-0.08,95 \%$ CI -0.14 to $-0.04, p=0.003)$. However, in another study, women were almost half as likely as men $(\mathrm{OR}=0.49,95 \% \mathrm{CI}=[0.35$ $-0.69]$ ) to hold leadership positions despite the number of research publications. ${ }^{58}$
White et $a l^{88}$ observed notable differences among women and men medical school deans in the type of advanced degrees (doctorate in male deans vs businessrelated degrees in female deans) and the rank of the deans' medical school education and training (more men graduating from the top 50 National Institute of Healthranked schools than women), presenting what seems like a probable association. Little or lack of mentorship was documented as a hindering factor to women seeking leadership. ${ }^{63}$

On what hinders women's enactment of leadership, three studies explored women's leadership through the perceptions of medical schools deans, ${ }^{61}$ faculty within psychiatry departments ${ }^{63}$ and faculty at one private medical college. ${ }^{5}$ For example, Pololi and colleagues ${ }^{5}$ reported that women faculty, in comparison to men, were less likely to perceive their institutions as family-friendly $(\mathrm{T}=-4.06, p<0.001)$, making efforts towards addressing gender diversity $(\mathrm{T}=-9.70, \mathrm{p}<0.001)$, and that their personal values were less congruent with institutional values $(\mathrm{T}=-2.06, p<0.05)$. Four studies addressed stereotyping and its effects on women's leadership. ${ }^{15} 636672$ Sexism was reported as a significant barrier to women faculty as they progressed in their careers in psychiatry departments $(p=0.0001){ }^{63}$

In a preintervention/postintervention, Girod et a $t^{66}$ investigated the association between implicit gender biases and leadership positions. The authors found that gender and age were significantly in favour of men $(\beta$ male $=0.18, \mathrm{p}=0.001 ; \beta$ age $=0.04, p=0.004$ ), suggesting that being an older male faculty is inherently associated with leadership than with other age and gender combinations.

\section{Impact of women's leadership programmes on leadership emergence and enactment}

Seven studies document the impact of women's leadership interventions on individual career satisfaction 626873758586 and on medical schools' environments. ${ }^{61}$ A positive effect of leadership development programmes was observed on the values, behaviours, style and actions women academicians embraced (table 3). In terms of values, one study evaluated leadership programmes through the perceptions of medical school deans. In their survey of US and Canadian medical school leadership, Dannels et $a l^{60}$ investigated the influence of the Executive Leadership in Academic Medicine (ELAM) programme on organisational climate. The authors report that deans had positive perceptions $(\mathrm{M}=5.62, \mathrm{SD}=0.961)$ of the ELAM programme and the influence brought to medical schools by its alumnae. ${ }^{61}$ The authors also found a significant difference between men and women deans in how they developed leadership in faculty, with women deans reporting more frequent use of practices than did men $(p=0.032)$. These practices included publicly supporting the person when she/he makes a difficult decision, appointing a faculty member to high-level committees or task forces and nominating faculty to leadership training outside the institution. 


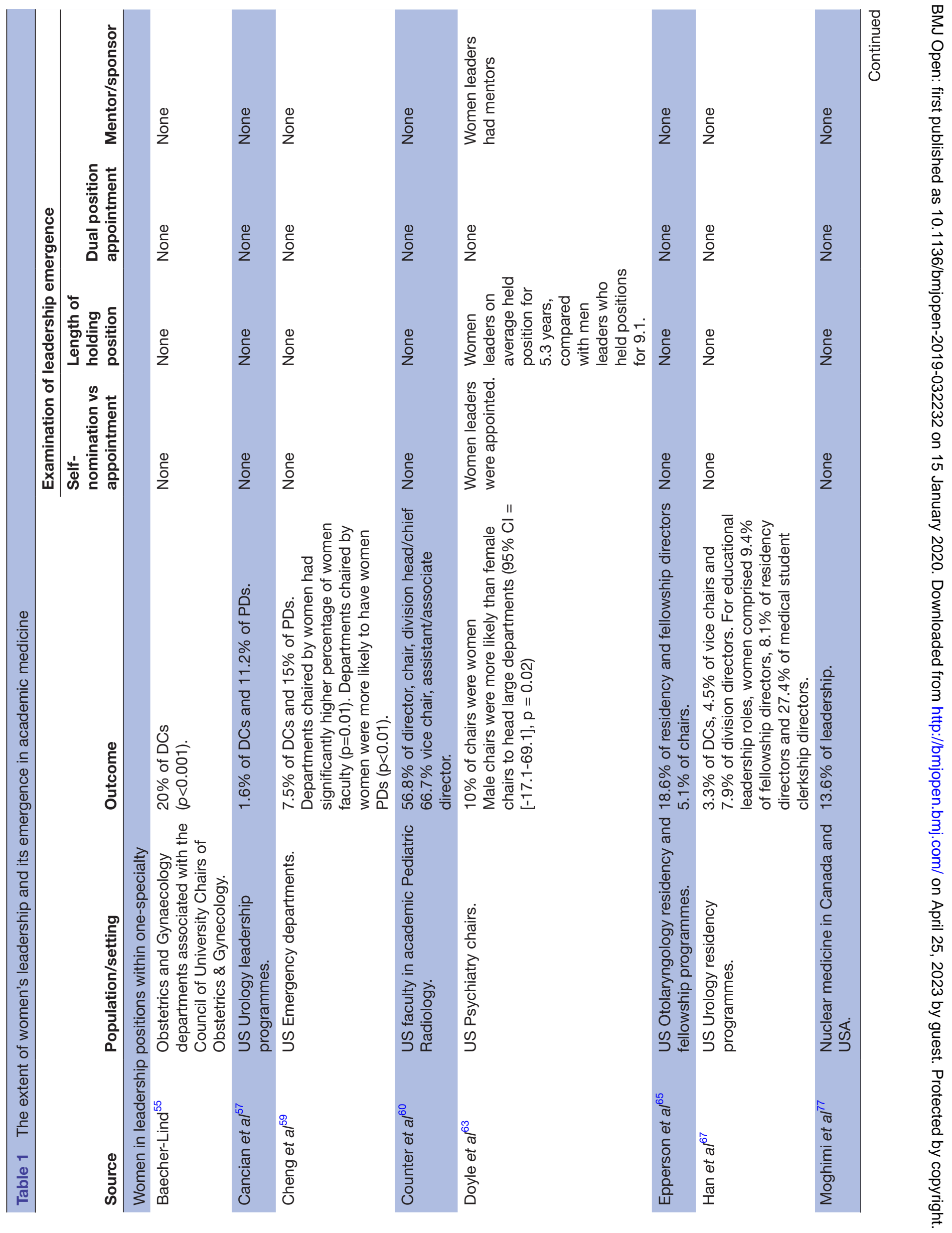




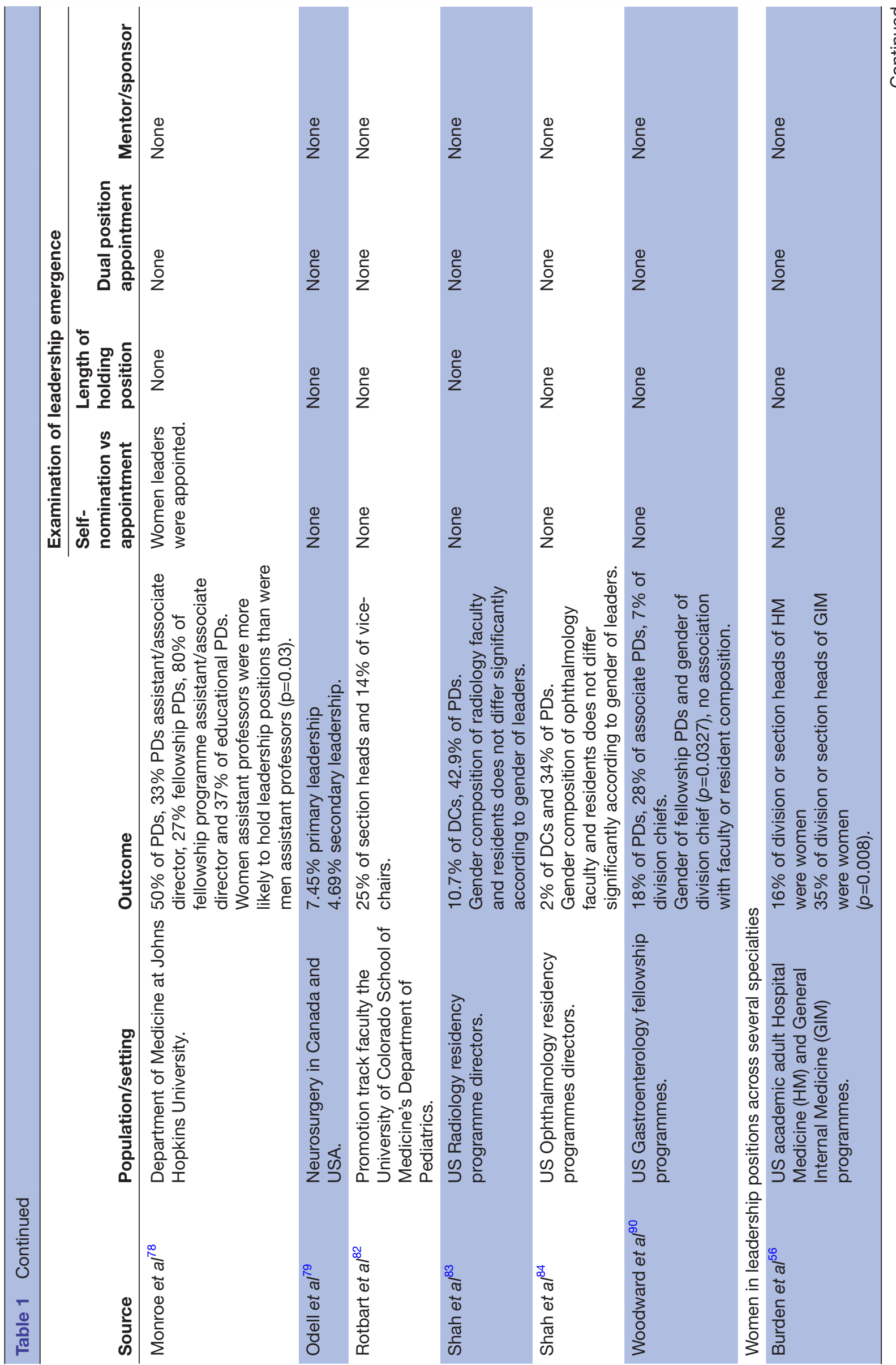




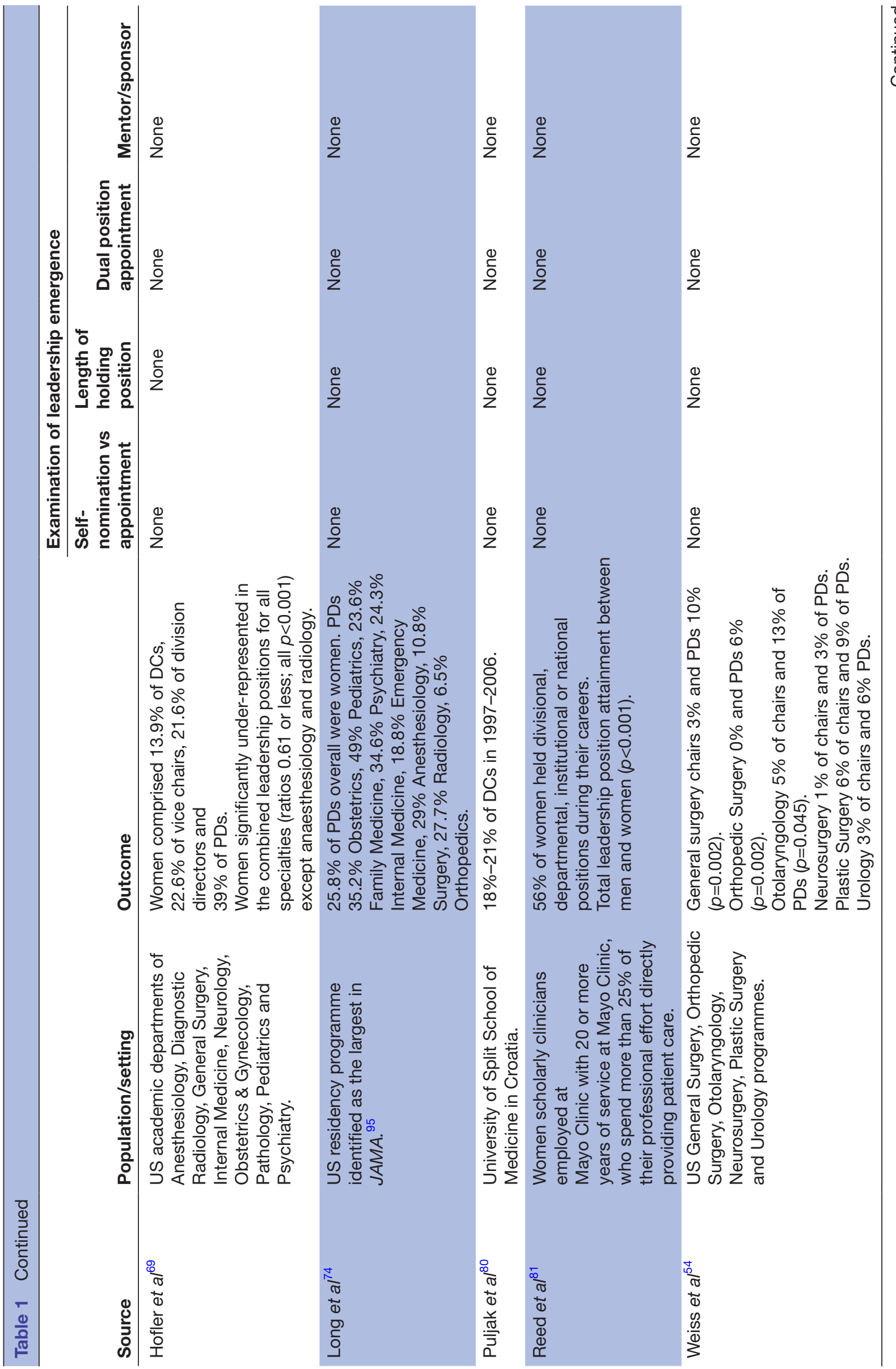




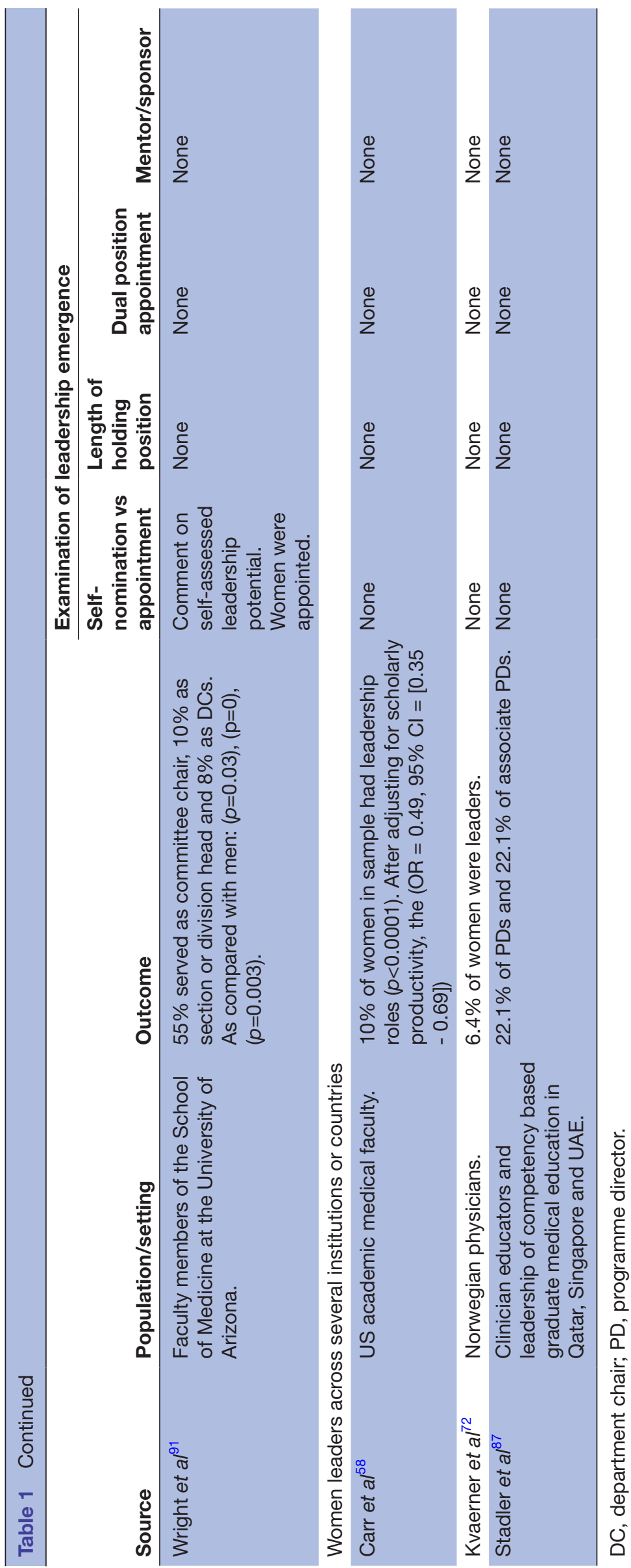

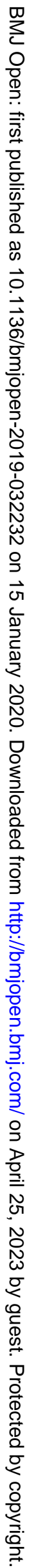


Table 2 Thematic analysis of the 16 quantitative articles that examined the hindering factors associated with women's leadership emergence and enactment

\begin{tabular}{|c|c|c|c|c|}
\hline Theme & Subtheme & Level & Outcome & Result \\
\hline \multirow[t]{6}{*}{$\begin{array}{l}\text { Leadership } \\
\text { emergence }\end{array}$} & \multirow[t]{3}{*}{$\begin{array}{l}\text { Research } \\
\text { production }\end{array}$} & \multirow[t]{3}{*}{ Institutional } & $\begin{array}{l}\text { Increased production of } \\
\text { research is associated with } \\
\text { leadership attainment. }\end{array}$ & $\begin{array}{l}\text { Senior leadership positions were more likely held } \\
\text { by male faculty despite research publications } \\
\left(\mathrm{OR}=0.49 ; 95 \% \mathrm{Cl}=[0.35-0.69] .{ }^{58}\right.\end{array}$ \\
\hline & & & $\begin{array}{l}\text { Timing of leadership } \\
\text { appointments (mid- } \\
\text { career) negatively affected } \\
\text { by modest research } \\
\text { production. }\end{array}$ & $\begin{array}{l}\text { Women published fewer articles throughout } \\
\text { their careers than men (Mean } \pm S D=29.5 \pm \\
28.8 \text { vs. } 75.8 \pm 60.3, p=0.001) . \text { However, after } \\
27 \text { years, women produced a mean of } 1.57 \\
\text { more publications annually than men }(p=0.001) \text {. } \\
\text { Throughout their careers, women held fewer } \\
\text { leadership roles than men }(p=0.001) .^{81}\end{array}$ \\
\hline & & & $\begin{array}{l}\text { Decreased research } \\
\text { production. }\end{array}$ & $\begin{array}{l}\text { Gender was indirectly significantly associated } \\
\text { with clinical position through publication activity } \\
(\beta=-0.08,95 \% \mathrm{Cl}=[-0.14 \text { to }-0.04], p=0.003) \text {. } \\
\text { The negative association between gender and } \\
\text { publication activity }(\beta=-0.21, p<0.001){ }^{70}\end{array}$ \\
\hline & Mentorship & Interpersonal & $\begin{array}{l}\text { Lack of mentorship may } \\
\text { hinder women from } \\
\text { becoming leaders. }\end{array}$ & $\begin{array}{l}\text { Women chairs were more likely than men chairs } \\
\text { to perceive barriers in their career development } \\
\text { citing little or no mentorship }(p=0.04) .^{63}\end{array}$ \\
\hline & $\begin{array}{l}\text { Time of } \\
\text { academic } \\
\text { appointment }\end{array}$ & - & $\begin{array}{l}\text { Entering academia } \\
\text { belatedly may contribute to } \\
\text { leadership disparities. }\end{array}$ & $\begin{array}{l}\text { Women faculty entered academia at a later } \\
\text { career stage, in part, resulted in women trying to } \\
\text { advance at a later stage than men in academic } \\
\text { position and tenure. } 82\end{array}$ \\
\hline & $\begin{array}{l}\text { Educational } \\
\text { background } \\
\text { and advanced } \\
\text { degrees }\end{array}$ & Institutional & $\begin{array}{l}\text { Educational background } \\
\text { and types of degrees } \\
\text { may influence leadership } \\
\text { selection. }\end{array}$ & $\begin{array}{l}\text { A greater percentage of male deans graduated } \\
\text { from the top } 50 \mathrm{NIH} \text {-ranked research-award } \\
\text { schools than women deans }\left(p=0.005, \omega^{2}=23.3 \% \text {, }\right. \\
\left.\eta^{2}=25.4 \%\right) \text {. } \\
\text { PhD or other doctorate degrees were more } \\
\text { prevalent among men deans as opposed to } \\
\text { business-related degrees among women (MBA, } \\
\text { MHA, MPH, or JD). }{ }^{88}\end{array}$ \\
\hline \multirow[t]{5}{*}{$\begin{array}{l}\text { Leadership } \\
\text { enactment }\end{array}$} & \multirow[t]{3}{*}{$\begin{array}{l}\text { Policy } \\
\text { development } \\
\text { and translation }\end{array}$} & Institutional & $\begin{array}{l}\text { Dismissal of work-life } \\
\text { balance measures. }\end{array}$ & $\begin{array}{l}\text { Out of the } 15 \text { family-friendly policies, only three } \\
\text { were available at more than } 68 \% \text { of medical } \\
\text { schools: benefits for part-time faculty, paid } \\
\text { maternity and paternity leave. }{ }^{61}\end{array}$ \\
\hline & & Institutional & $\begin{array}{l}\text { Dismissal of diversity and } \\
\text { inclusion measures. }\end{array}$ & $\begin{array}{l}\text { Fewer than } 14 \% \text { of schools implemented gender } \\
\text { equity specific policies. }{ }^{61} \\
\text { Women faculty showed more negative } \\
\text { perceptions on equity for women }(T=-19.82 \text {, } \\
p<0.001) \text {; institutional change efforts for diversity } \\
(T=-9.70, p<0.001) .^{5}\end{array}$ \\
\hline & & Institutional & $\begin{array}{l}\text { Incongruence between } \\
\text { organisational values and } \\
\text { individual values. }\end{array}$ & $\begin{array}{l}\text { Women faculty showed more negative } \\
\text { perceptions on values alignment }(T=-2.06 \text {, } \\
p<0.05) .{ }^{5}\end{array}$ \\
\hline & \multirow[t]{2}{*}{ Stereotyping } & Institutional & $\begin{array}{l}\text { Existence of gendered } \\
\text { language in leadership } \\
\text { associated policies. }\end{array}$ & $\begin{array}{l}\text { Being a leader is associated with being male } \\
\text { (Mean } \pm \mathrm{SD}=2.4 \pm 2.2, \mathrm{OR}=6,95 \mathrm{Cl} \%=[1.02 \\
\text { - 35.37]) and traditionally male associated traits: } \\
\text { analytical }(\mathrm{M}=2.5, \mathrm{SD}=2.4) ; \text { independent (Mean } \\
\pm \mathrm{SD}=3.1 \pm 2.6, \mathrm{OR}=1,95 \mathrm{Cl} \%=[0.2-5.1]) ; \\
\text { individualistic (Mean } \pm \mathrm{SD}=1.8 \pm 1.5, \mathrm{OR}=1,95 \\
\mathrm{Cl} \%=[0.2-5.4]) .{ }^{15}\end{array}$ \\
\hline & & Interpersonal & $\begin{array}{l}\text { Existence of implicit gender } \\
\text { bias, favouring men as } \\
\text { leaders. }\end{array}$ & $\begin{array}{l}\text { Slight implicit preference for men leaders over } \\
\text { women (IAT D score=0.16, SD=0.42). }{ }^{66}\end{array}$ \\
\hline
\end{tabular}




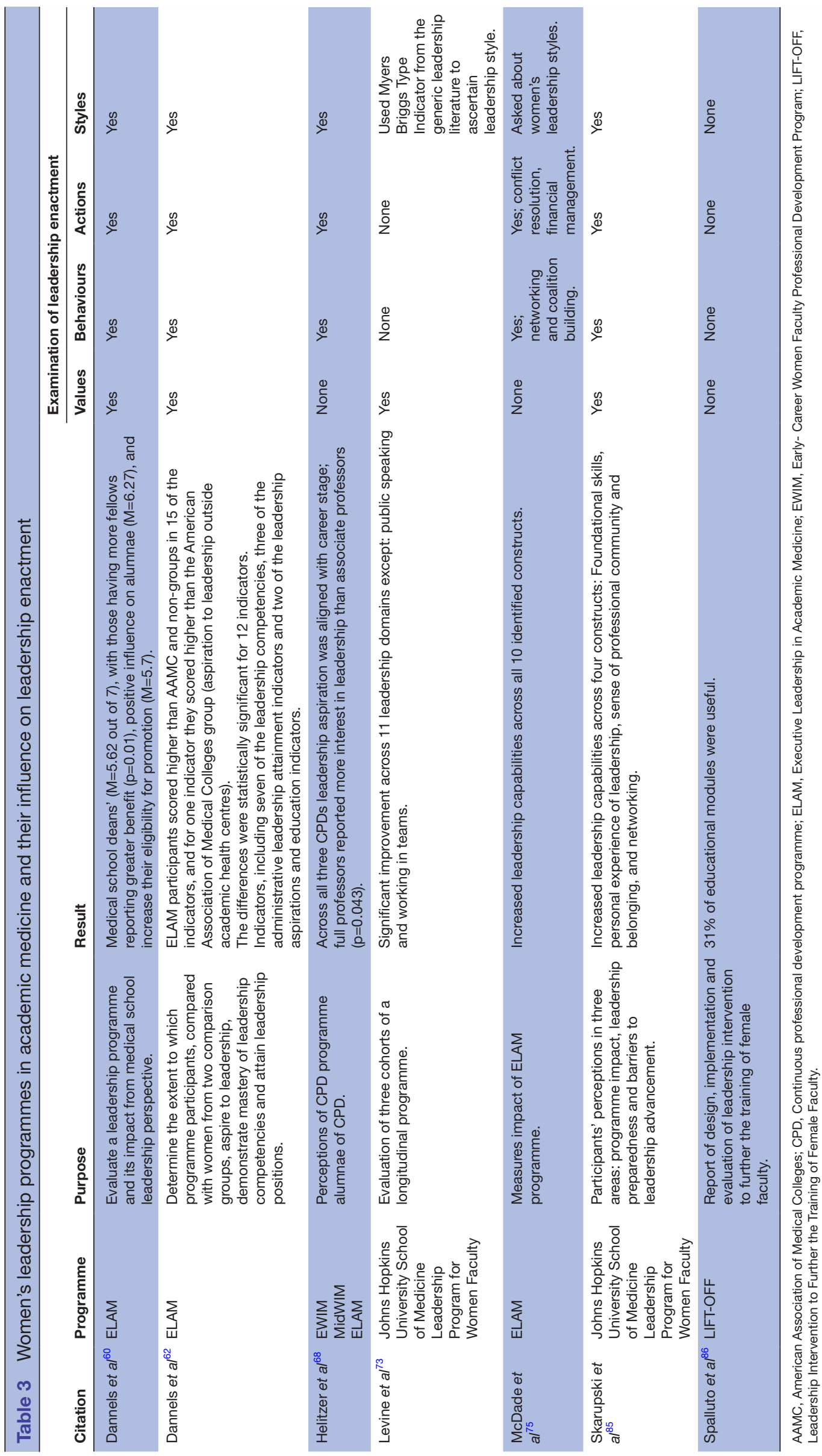


In terms of behaviours, styles and actions, programmes improved women's negotiation skills ${ }^{687375}$ and provided networking opportunities. ${ }^{68737586}$ Alumnae of leadership programmes were more likely to attain leadership positions, ${ }^{62} 86$ they were more likely to have knowledge and confidence in leadership skills, and were more likely to have knowledge of organisational structures and processes. ${ }^{62}$ Most studies employed a predesign/postdesign to evaluate leadership programmes.

\section{DISCUSSION}

To our knowledge, this systematic review is the first that synthesises evidence on women's leadership in academic medicine. The 40 studies address three themes: the extent of women's leadership and its emergence; factors influencing their leadership emergence and enactment; the impact of leadership development programmes on women's leadership. Deeper analysis revealed that included studies are levered by imperceptible underpinnings. Oriented by a positivist paradigm, it seems much of the reviewed literature inadvertently embraced a narrow understanding of leadership, creating institute-centric rather than women-centric scholarship. Drawing on the findings of our review, in what follows, we unsettle the conceptual foundation of the reviewed studies. We argue that women's leadership studies provide a mere diversity/ inclusion performance indicator for institutes that does not necessarily serve women. We then argue the need to shift to a more nuanced women-centric understanding of leadership.

\section{Leadership as organisational position}

Our review revealed that in medical schools, women had less access to leadership positions, the evidence showed fewer than $50 \%$ of leadership positions-chairs, programme directors, or unit heads-were occupied by women faculty members (table 1). Rooted in understanding leadership as occupancy of an organisational position, in what Northouse ${ }^{43}$ calls assigned leadership, nearly $60 \%$ of the studies' main objective was to document the gender distribution of leadership positions, and often to correlate this with the number of faculty or residents who are women. This conceptualisation is based on a positivist understanding of leadership, which ultimately sees leadership as a quantifiable variable. The rationale for this approach may be that determining gender ratio in leadership will establish a performance indicator for the institute in terms of inclusion and diversity that is, the number of women in leadership reflects gender equity/ inequity. We question the benefit of this reduction to women leaders. Although we do not think the two are in conflict, we believe institute-centric thinking neglects the value women leaders bring to leadership and the organisational complexities they must navigate to become leaders. Leadership is not merely an organisational position for women faculty to occupy. Moreover, the number of women occupying leadership positions at a given point in time, an idea perpetuated by the pipeline metaphor, ${ }^{10}$ does not by itself reflect equity in leadership. Indeed, the goal is not a critical mass of women who are assigned leaders but 'a critical mass of women with sustained success as leaders'. ${ }^{47}$

Most studies that examined gender distribution neglected women's emergence as leaders. It is for this reason, and drawing on Northouse's ${ }^{43}$ work, that we devised a metric (table 1). Although not exhaustive, the qualitative metric is an initial attempt to introduce the construct of leadership emergence into the discourse on women's leadership in academic medicine. For example, we found that only two studies commented on women being appointed, ${ }^{6378}$ and no studies mentioned whether women self-nominated. Our intuition is that informal leadership is common among women but whether they self-nominate for formal leadership remains to be seen.

Furthermore, even within the parameters of positivist thinking, all studies are methodologically poor, having a MERSQI range of $7-12.5$. Of the 40 studies, $62.5 \%$ were cross-sectional. Most studies used websites (which may be outdated or inaccurate, compromising the validity of the findings) or self-reported surveys for data. The median response rates where questionnaires were used was $60 \%$ (range 22\%-100\%). Many studies failed to explain how their questionnaires were developed or if they were validated.

\section{Leadership as process of influence}

Recognising the limitation of a positivist paradigm, we suggest a women-centric approach. This understanding aligns with organisational traditions, where leadership is conceptualised as a process of influence between leader and followers ${ }^{439293}$; that is a series of actions and exchanges take place at the interpersonal level for leadership to occur. Here scholars recognise the importance of a leader's capacity for influence and how such influence shapes culture. ${ }^{42} 4394$

First, to explore capacity for influence, we put women at the heart of inquiry: what are women's leadership capacities; that is their motivations, knowledge, skills and experiences? Many studies did not mention whether women aspired to leadership. Many studies assumed prior leadership knowledge among their respondents, a few mentioned formal leadership trainings and only one documented the role of mentors. ${ }^{63}$

We found instead, that studies focused on what hinders women's leadership at an institutional level such as requirement of research production ${ }^{58} 7081$ and certain educational backgrounds ${ }^{88}$ and at an interpersonal-level for example, gender bias. ${ }^{66}$ We believe such study objectives are important. However, they may steer women, who aspire to leadership, towards meeting institutional requirements that are not necessarily crucial to becoming a leader. Indeed, Carr et $a \bar{l}^{58}$ showed that women were almost half as likely as men $(\mathrm{OR}=0.49,95 \%$ CI $[0.35$ $0.69]$ ) to hold leadership positions despite the number of research publications. By studying what the institute 
seemingly requires, studies that focus on hindering factors make scholarship on women's leadership institute-centric.

To be women-centric, we grouped hindering factors to the stage of leadership (emergence and enactment) where we believe such factors manifest (table 2), then we grouped these studies according to the perspective each one took, whether institutional, interpersonal, or individual. Both categorisation bring focus to women's capacities for leadership and how they can be best developed.

For example, beyond documenting lack of mentorship, ${ }^{63}$ the first categorisation prompt us to consider mentorship according to leadership stage. Do women leaders need mentors to emerge as leaders or when they are enacting leadership? Such a distinction draws focus to different nuanced elements. Studying mentoring relationships at an emergence stage may deepen our understanding of women's motivation or lack thereof for leadership. While studying mentoring relationships at an enactment stage may deepen our understanding of women's length of service in formal positions, and the leadership knowledge and skills they gain because of such relationship. This is especially important because, while we found studies that examined hindering factors on the institutional level, for example, policy implementation ${ }^{60}$ and the interpersonal level, for example, gender bias, ${ }^{66}$ we did not find studies that examined barriers on the individual level for example, lack of motivation, knowledge, or skills among women.

Second, social interactions are the essence of leadership and in time produce culture; the values and beliefs that govern our behaviours in organisations. ${ }^{42}$ From our review, the current culture, is shaped by stereotypical beliefs $^{5156065}$ and a lack of gender equality policy development and implementation. ${ }^{60}$ This culture may sometimes feel static and unchanging, but it is recreated and reinforced in the daily interactions. In the proposed conceptualisation, we come to recognise that culture and leadership are two sides of the same coin, ${ }^{441}$ understanding one requires exploring the other.

Once more we put women at the heart of inquiry: how do women leaders shape culture? From our review, many studies neglected women's enactment of leadership. Many studies did not mention whether women had informal leadership roles, in what Northouse ${ }^{43}$ calls emergent leadership (leadership that develops organically and is based on building alignments and fostering trust). Many studies did not mention what values informed women's decisions, what behaviours they modelled, or what actions they took to improve the quality of medical education and practice whether formally or informally. Many studies did not explore the leadership styles women embraced.

Addressing these gaps situates women leaders as critical actors in culture change ${ }^{224547}$ and conceptually grounds women's leadership in their lived experiences and not the broader generic leadership literature. ${ }^{17}$ The exception to the rule is studies examining leadership development programmes. ${ }^{62} 6873758586$ Such programmes may be an ideal place to explore women's emergence and enactment of leadership. We found leadership development programme studies paid attention to the values, behaviours, actions and styles women embraced and enacted (table 3 ).

\section{Study limitations}

Our study has some limitations. First, we restricted the review to quantitative literature and argued for studying contextual organisational nuances, which might have been explored in qualitative studies. Second, we defined leadership as a process of influence between leaders and followers but have limited our discussion to the leader's perspective. Third, we found that all studies except one $^{87}$ were conducted in North America and Europe. As a result, the presented evidence may not reflect nonwestern contexts, but we have forgone discussion of this finding. Addressing these limitations requires more space and further research which we hope to embark on and invite others to do so.

\section{CONCLUSION}

After reviewing the quantitative literature on women's leadership, we recognise the need for broader conceptual foundations. We also recognise that in problematising the current conceptual foundation, we join other scholars $^{5} 17224753$ in arguing for more innovative research questions and rigorous methods. Our argument for broadening the conceptual foundation is two-fold. First, by focusing on women's experiences, we can offer readership of this field, who we assume are largely women faculty, practical knowledge that can help them pursue their own leadership. Second, leadership and culture are inextricably linked. ${ }^{47}$ Consequently, the culture change we aspire to in academic medicine cannot happen without a deeper understanding of this relationship.

Twitter Lulu Alwazzan @alwazzan_L and Samiah S Al-Angari @SamiahAlan

Contributors LA is responsible for the study's conception, design and conceptual argument. LA and SSA-A collected, analysed, interpreted and discussed the data. LA and SSA-A wrote the manuscript.

Funding The authors have not declared a specific grant for this research from any funding agency in the public, commercial or not-for-profit sectors.

Competing interests None declared.

Patient consent for publication Not required.

Provenance and peer review Not commissioned; externally peer reviewed.

Data availability statement The data from the current study may be requested from the corresponding author.

Open access This is an open access article distributed in accordance with the Creative Commons Attribution Non Commercial (CC BY-NC 4.0) license, which permits others to distribute, remix, adapt, build upon this work noncommercially, and license their derivative works on different terms, provided the original work is properly cited, appropriate credit is given, any changes made indicated, and the use is non-commercial. See: http://creativecommons.org/ licenses/by-nc/4.0/.

ORCID iDs

Lulu Alwazzan http://orcid.org/0000-0002-8403-8588

Samiah S Al-Angari https://orcid.org/0000-0002-8950-0524 


\section{REFERENCES}

1 AAMC. Diversity in medical education, 2016. Available: https://www. aamcdiversityfactsandfigures2016.org [Accessed June 13, 2018].

2 Dogra N. The development and evaluation of a programme to teach cultural diversity to medical undergraduate students. Med Educ 2001;35:232-41.

3 Tsouroufli M, Malcolm I. Equality, diversity and fairness in medical education: international perspectives. Med Educ 2015;49:4-6.

4 Pololi LH. Changing the culture of academic medicine: perspectives of women faculty. Lebanon, NH: UPNE, 2010.

5 Pololi LH, Civian JT, Brennan RT, et al. Experiencing the culture of academic medicine: gender matters, a national study. J Gen Intern Med 2013;28:201-7.

6 Reed V, Buddeberg-Fischer B. Career obstacles for women in medicine: an overview. Med Educ 2001;35:139-47.

7 Risberg G, Johansson EE, Hamberg K. 'Important... but of low status': male education leaders' views on gender in medicine. Med Educ 2011;45:613-24.

8 Valantine $\mathrm{H}$, Sandborg $\mathrm{Cl}$. Changing the culture of academic medicine to eliminate the gender leadership gap. Acad Med 2013;88:1411-3.

9 Bickel J, Wara D, Atkinson BF, et al. Increasing women's leadership in academic medicine: report of the AAMC project implementation Committee. Acad Med 2002;77:1043-61.

10 Magrane D, Morahan PS. Fortifying the Pipeline to Leadership: The International Center for Executive Leadership in Academics at Drexel. In: Rachelle S. Heller S, Sabila PS, eds. Forward to professorship in stem: inclusive faculty development strategies that work. San Diego, CA: Academic Press, 2016: 319-36.

11 Morahan P, Bickel J. Capitalizing on Women's intellectual capital in the professions. Acad Med 2002;77:110-2.

12 Isaac C, Lee B, Carnes M. Interventions that affect gender bias in hiring: a systematic review. Acad Med 2009;84:1440-6.

13 Travis EL, Doty L, Helitzer DL. Sponsorship: a path to the academic medicine C-suite for women faculty? Acad Med 2013;88:1414-7.

14 Burgess DJ, Joseph A, van Ryn M, et al. Does stereotype threat affect women in academic medicine? Acad Med 2012;87:506-12.

15 Marchant A, Bhattacharya A, Carnes M. Can the language of Tenure criteria influence women's academic advancement? J Womens Health 2007;16:998-1003.

16 Alwazzan L, Rees CE. Women in medical education: views and experiences from the Kingdom of Saudi Arabia. Med Educ 2016;50:852-65.

17 McKimm J, Da Silva AS, Edwards S, et al. Women and leadership in medicine and medical education: international perspectives. in: international perspectives on equality, diversity and inclusion. London: Emerald Group Publishing Limited, 2015: Vol 2. 69-98.

18 Laver KE, Prichard IJ, Cations M, et al. A systematic review of interventions to support the careers of women in academic medicine and other disciplines. BMJ Open 2018;8:e020380.

19 Edmunds LD, Ovseiko PV, Shepperd S, et al. Why do women choose or reject careers in academic medicine? A narrative review of empirical evidence. The Lancet 2016;388:2948-58.

20 Penny M, Jeffries R, Grant J, et al. Women and academic medicine: a review of the evidence on female representation. $J$ R Soc Med 2014:107:259-63.

21 Pololi LH, Krupat E, Civian JT, et al. Why are a quarter of faculty considering leaving academic medicine? A study of their perceptions of institutional culture and intentions to leave at 26 representative U.S. medical schools. Academic Medicine 2012;87:859-69.

22 Helitzer DL, Newbill SL, Cardinali G, et al. Changing the culture of academic medicine: critical mass or critical actors? J Womens Health 2017;26:540-8.

23 Pololi LH, Jones SJ. Women faculty: an analysis of their experiences in academic medicine and their coping strategies. Gend Med 2010;7:438-50.

24 Pololi L, Kern DE, Carr P, et al. The culture of academic medicine: faculty perceptions of the lack of alignment between individual and institutional values. J Gen Intern Med 2009;24:1289-95.

25 Cook AF, Arora VM, Rasinski KA, et al. The prevalence of medical student mistreatment and its association with burnout. Acad Med 2014;89:749-54.

26 Frank E, Carrera JS, Stratton T, et al. Experiences of belittlement and harassment and their correlates among medical students in the United States: longitudinal survey. BMJ 2006;333.

27 Komaromy M, Bindman AB, Haber RJ, et al. Sexual harassment in medical training. N Engl J Med Overseas Ed 1993;328:322-6.

28 Kwok S, Ostermeyer B, Coverdale J. A systematic review of the prevalence of patient assaults against residents. J Grad Med Educ 2012;4:296-300.
29 Chaimowitz GA, Moscovitch A. Patient assaults on psychiatric residents: the Canadian experience. Can J Psychiatry 1991;36:107-11.

30 Cohen JS, Leung Y, Fahey M, et al. The happy docs study: a Canadian association of Internes and residents well-being survey examining resident physician health and satisfaction within and outside of residency training in Canada. BMC Res Notes 2008;1:105

31 Cohen JS, Patten S. Well-Being in residency training: a survey examining resident physician satisfaction both within and outside of residency training and mental health in Alberta. BMC Med Educ 2005;5.

32 Hoosen IA, Callaghan R. A survey of workplace bullying of psychiatric trainees in the West Midlands. Psychiatr Bull 2004;28:225-7.

33 Keeley PW, Waterhouse ET, Noble SI. Prevalence and characteristics of bullying of trainees in palliative medicine. Palliat Med 2005;19:84-5.

34 Nicolson P, Welsh CL. Sexual harassment, male dominated organizations and the role of counselling psychology: the case of medical school. Couns Psychol Q 1993;6:291-301.

35 National initiative on gender, culture and leadership in medicine: C-Change. Available: http://cchange.brandeis.edu [Accessed 27 Feb 2019].

36 Conrad P, Carr P, Knight S, et al. Hierarchy as a barrier to advancement for women in academic medicine. $J$ Womens Health 2010;19:799-805.

37 Pololi L, Cooper LA, Carr P. Race, disadvantage and faculty experiences in academic medicine. J Gen Intern Med 2010;25:1363-9.

38 Pololi L, Conrad P, Knight S, et al. A study of the relational aspects of the culture of academic medicine. Acad Med 2009;84:106-14.

39 Pololi LH, Evans AT, Civian JT, et al. Faculty Vitality-Surviving the challenges facing academic health centers: a national survey of medical faculty. Acad Med 2015;90:930-6.

40 Pololi LH, Evans AT. Group peer mentoring: an answer to the faculty mentoring problem? A successful program at a large academic department of medicine. J Contin Educ Health Prof 2015;35:192-200.

41 Pololi LH, Krupat E, Schnell ER, et al. Preparing culture change agents for academic medicine in a multi-institutional consortium: the $\mathrm{C}$ - change learning action network. J Contin Educ Health Prof 2013;33:244-57.

42 Schein EH. Organizational culture and leadership. 5th ed. Hoboken, NJ: Wiley, 2016.

43 Northouse PG. Leadership: theory and practice. 7th ed. Thousand Oak, CA: Sage Publications, 2016.

44 Kirch DG. Presidential address to AAMC 2007: culture and the courage to change. Available: https://www.aamc.org/download/ 169722/data/kirchspeech2007.pdf [Accessed February 2019].

45 Magrane D, Helitzer D, Morahan P, et al. Systems of career influences: a conceptual model for evaluating the professional development of women in academic medicine. $J$ Womens Health 2012;21:1244-51.

46 McKimm J, Wong J, Wright R, et al. Developing clinical leadership capacity among UK Foundation trainees. Br J Hosp Med 2011;72:406-9.

47 Morahan PS, Rosen SE, Richman RC, et al. The leadership continuum: a framework for organizational and individual assessment relative to the advancement of women physicians and scientists. $J$ Womens Health 2011;20:387-96.

48 Moher D, Liberati A, Tetzlaff J, et al. Preferred reporting items for systematic reviews and meta-analyses: the PRISMA statement. PLoS Med 2009;6:e1000097.

49 Haig A, Dozier M. BEME guide no 3: systematic searching for evidence in medical education-Part 1: sources of information. Med Teach 2003;25:352-63.

50 Haig A, Dozier M, No BG. BEME Guide No. 3: Systematic searching for evidence in medical education--Part 2: Constructing searches. Med Teach 2003;25:463-84.

51 Reed DA, Cook DA, Beckman TJ, et al. Association between funding and quality of published medical education research. JAMA 2007;298:1002-9.

52 Hofler L, Hacker MR, Dodge LE, et al. Subspecialty and gender of obstetrics and gynecology faculty in department-based leadership roles. Obstet Gynecol 2015;125:471-6.

53 Morahan PS, Gleason KA, Richman RC, et al. Advancing women faculty to senior leadership in US academic health centers: fifteen years of history in the making. J Women High Educ 2010;3:140-65.

54 Weiss A, Lee KC, Tapia V, et al. Equity in surgical leadership for women: more work to do. Am J Surg 2014;208:494-8. 
55 Baecher-Lind L. Women in leadership positions within obstetrics and gynecology: does the past explain the present? Obstet Gynecol 2012;120:1415-8.

56 Burden M, Frank MG, Keniston A, et al. Gender disparities in leadership and scholarly productivity of academic hospitalists. J Hosp Med 2015;10:481-5.

57 Cancian M, Aguiar L, Thavaseelan S. The representation of women in urological leadership. Urol Pract 2018;5:228-32.

58 Carr PL, Raj A, Kaplan SE, et al. Gender differences in academic medicine: retention, RANK, and leadership comparisons from the National faculty survey. Acad Med 2018;93:1694-9.

59 Cheng D, Promes S, Clem K, et al. Chairperson and faculty gender in academic emergency medicine departments. Acad Emerg Med 2006;13:904-6.

60 Dannels S, McLaughlin J, Gleason KA, et al. Medical schoo deans' perceptions of organizational climate: useful indicators for advancement of women faculty and evaluation of a leadership program's impact. Acad Med 2009;84:67-79.

61 Counter WB, Khurshid K, Jala S, et al. Gender differences among academic paediatrics radiology faculty in the United States and Canada. Acad Radiol.

62 Dannels SA, Yamagata H, McDade SA, et al. Evaluating a leadership program: a comparative, longitudinal study to assess the impact of the executive leadership in academic medicine (ELAM) program for women. Acad Med 2008;83:488-95.

63 Doyle M, Pederson A, Meltzer-Brody S. Demographic and personal characteristics of male and female chairs in academic psychiatry. Acad Psychiatry 2016;40:402-9.

64 Ellinas EH, Fouad N, Byars-Winston A. Women and the decision to leave, Linger, or lean in: predictors of intent to leave and aspirations to leadership and advancement in academic medicine. $J$ Womens Health 2018;27:324-32.

65 Epperson M, Gouveia CJ, Tabangin ME, et al. Female representation in otolaryngology leadership roles. The laryngoscope; 14.

66 Girod S, Fassiotto M, Grewal D, et al. Reducing implicit gender leadership bias in academic medicine with an educational intervention. Acad Med 2016;91:1143-50.

67 Han J, Stillings S, Hamann H, et al. Gender and subspecialty of urology faculty in Department-based leadership roles. Urology 2017;110:36-9.

68 Helitzer DL, Newbill SL, Morahan PS, et al. Perceptions of skill development of participants in three national career development programs for women faculty in academic medicine. Acad Med 2014;89:896-903.

69 Hofler LG, Hacker MR, Dodge LE, et al. Comparison of women in department leadership in obstetrics and gynecology with those in other specialties. Obstet Gynecol 2016;127:442-4.

70 Komlenac N, Gustafsson Sendén M, Verdonk P, et al. Parenthood does not explain the gender difference in clinical position in academic medicine among Swedish, Dutch and Austrian physicians. Adv Health Sci Educ 2019;24:539-57.

71 Kuhlmann E, Ovseiko PV, Kurmeyer C, et al. Closing the gender leadership gap: a multi-centre cross-country comparison of women in management and leadership in academic health centres in the European Union. Hum Resour Health 2017;15.

72 Kvarner KJ, Aasland OG, Botten GS. Female medical leadership: cross sectional study. BMJ 1999;318:91-4.

73 Levine RB, González-Fernández M, Bodurtha J, et al. Implementation and evaluation of the Johns Hopkins University school of medicine leadership program for women faculty. $J$ Womens Health 2015;24:360-6.
74 Long TR, Elliott BA, Warner ME, et al. Resident and program director gender distribution by specialty. J Womens Health 2011;20:1867-70.

75 McDade SA, Richman RC, Jackson GB, et al. Effects of participation in the executive leadership in academic medicine (ELAM) program on women faculty's perceived leadership capabilities. Acad Med 2004;79:302-9

76 McLean MR, Morahan PS, Dannels SA et al. Geographic mobility advances careers: study of the executive leadership in academic medicine (ELAM) program for women. Acad Med 2013;88:1700-6.

77 Moghimi S, Khurshid K, Jalal S, et al. Gender differences in leadership positions among academic nuclear medicine specialists in Canada and the United States. Am J Roentgenol 2019;212:146-50.

78 Monroe AK, Levine RB, Clark JM, et al. Through a gender lens: a view of gender and leadership positions in a department of medicine. $J$ Womens Health 2015;24:837-42.

79 Odell T, Toor H, Takayanagi A, et al. Gender disparity in academic neurosurgery. Cureus;11:e4628.

80 Puljak L, Kojundzic SL, Sapunar D. Gender and academic medicine: a good pipeline of women graduates is not advancing. Teach Learn Med 2008;20:273-8

81 Reed DA, Enders F, Lindor R, et al. Gender differences in academic productivity and leadership appointments of physicians throughout academic careers. Acad Med 2011;86:43-7.

82 Rotbart HA, McMillen D, Taussig H, et al. Assessing gender equity in a large academic department of pediatrics. Acad Med 2012;87:98-104.

83 Shah A, Braga L, Braga-Baiak A, et al. The association of departmental leadership gender with that of faculty and residents in radiology. Acad Radiol 2007;14:998-1003.

84 Shah DN, Volpe NJ, Abbuhl SB, et al. Gender characteristics among academic ophthalmology leadership, faculty, and residents: results from a cross-sectional survey. Ophthalmic Epidemiol 2010;17:1-6.

85 Skarupski KA, Levine RB, Rand C, et al. Impact of a leadership program for women faculty: a retrospective survey of eight years of cohort participants. J Fac dev 2019;33:7-14.

86 Spalluto LB, Spottswood SE, Deitte LA, et al. A leadership intervention to further the training of female faculty (LIFT-OFF) in radiology. Acad Radiol 2017;24:709-16.

87 Stadler DJ, Archuleta S, Ibrahim H, et al. Gender and international clinician educators. Postgrad Med J 2017;93:719-24.

88 White FS, McDade S, Yamagata H, et al. Gender-Related differences in the pathway to and characteristics of U.S. medical school deanships. Acad Med 2012;87:1015-23.

89 Willett LL, Halvorsen AJ, McDonald FS, et al. Gender differences in salary of internal medicine residency directors: a national survey. Am J Med 2015;128:659-65.

90 Woodward Z, Rodriguez Z, Jou JH, et al. Gender disparities in gastroenterology fellowship director positions in the United States. Gastrointest Endosc 2017;86:595-9.

91 Wright AL, Schwindt LA, Bassford TL, et al. Gender differences in academic advancement: patterns, causes, and potential solutions in one us College of medicine. Acad Med 2003;78:500-8.

92 Bass BM, Bass R. The bass Handbook of leadership: theory, research, and managerial applications. 4th ed. New York, NY: Free Press, 2008.

93 Tannenbaum R, Weschler IR, Massarik F. Leadership and organization: a behavioral science approach. Whitefish, MT: Literary Licensing, LLC, 2012.

94 Schein EH. Humble inquiry: the gentle art of asking instead of telling, 1st ED. San Francisco, CA: Berrett-Koehler Publishers, 2013.

95 Brotherton SE, Etzel SI. Graduate medical education, 2009-2010. JAMA 2010;304:1255-70. 